\title{
Mutações epistemológicas e o ensino da literatura: o advento do sujeito leitor
}

Annie Rouxel ${ }^{1}$

Tradução de Samira Murad

ReSuMO: O reconhecimento do sujeito leitor e de sua criatividade na elaboração do sentido foi acompanhado por importantes avanços teóricos com relação ao conhecimento dos leitores reais. Nosso interesse neste artigo é a leitura subjetiva, a forma pela qual os leitores investem-se no texto, reconfigurando-o de modo a transformá-lo em um "texto do leitor". A identificação, a reficcionalização do texto e a interleitura, todos esses fenômenos intervêm na relação com o texto que se instaura durante a leitura, sendo compreendidos como formas equivalentes de implicação. O ensino da literatura tira partido desses saberes por meio da aceitação das leituras singulares, ponto de partida das interpretações, dando espaço à intersubjetividade na sala de aula, compreendida agora como comunidade interpretativa.

Palavras-chaVE: Sujeito leitor, leitura literária, subjetividade, implicação, texto do leitor, biblioteca interior. ABSTRACT: The recognition of the reader as a subject and of her creativity in meaning elaboration have been accompanied by important theoretical advances in the knowledge of real readers. Nowadays, we take an interest in subjective reading; in the way the reader engages with the text she reads, reconfiguring it in order to make it her own. Identification, refictionalization of the text and interreading, these phenomena affect the relationship to the text that is established during the reading process, and are equally important forms of involvement.

The teaching literature draws from this awareness and uses individual texts as starting points for interpretation, allowing space for intersubjectivity within the class, which is, in turn, seen as an interpretative community. KEYWORDS: Reader as a subject, literary reading, subjectivity, involvement, reader's text, internal library.

RÉSU MÉ: La reconnaissance du sujet lecteur et de sa créativité dans l'élaboration du sens s'accompagne d’importantes avancées théoriques relatives à la connaissance des lecteurs réels. Désormais on s’intéresse la lecture subjective, à la manière dont les lecteurs s’investissent dans le texte lu et le reconfigurent pour en faire leur « texte de lecteur ». Identification, refictionnalisation du texte, interlecture, ces phénomènes interviennent dans le rapport au texte qui s’instaure au cœur de la lecture et ils sont appréciés comme autant de formes d'implication. L'enseignement de la littérature tire parti de ces savoirs en accueillant les lectures singulières, points de départ des interprétations, et en donnant place à l’intersubjectivité au sein de la classe conçue comme communauté interprétative.

MoTS CLÉS: Sujet lecteur; lecture littéraire; subjectivité; implication; texte du lecteur; bibliothèque intérieure.

É chegado o momento de dar o máximo de visibilidade ao engajamento do leitor em uma prática ativa. (BELLEMIN-NOËL, 2001, p. 21)

1 Professora Emérita de Língua e Literatura Francesa da Universidade Bordeaux 4. Sua pesquisa gira em torno da teoria e do ensino da leitura literária. Autora de Enseigner la lecture littéraire (1996), publicou, em colaboração com Gérard Langlade, Le sujet lecteur - Lecture subjective et enseignement da la littérature (2004), cuja tradução em português, de iniciativa de Neide Lucia de Rezende, será lançado no Brasil em 2012. Annie Rouxel publicou também com Brigitte Luichon Du corpus scolaire à la bibliothèque intérieure (2009). Contato : ani.rouxel@orange.fr
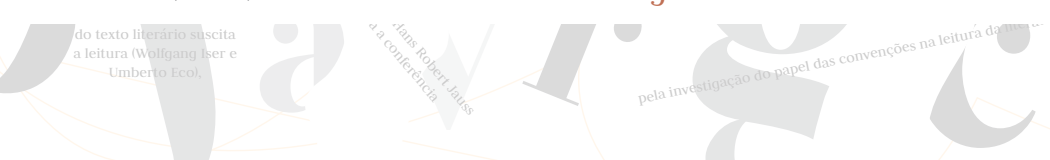
Em 2004, aconteceu em Rennes o colóquio "Sujeitos leitores e ensino de literatura", que marca a entrada na noção de sujeito leitor no campo da didática da literatura. O contexto do momento era marcado pela crise da leitura... escolar. De fato, se os estudos sociológicos estiverem corretos (BAUDELOT; CARTIER; DETREZ, 1999), a falta de interesse dos jovens pela leitura merge na escola, no momento em que essa atividade torna-se um exercício escolar avaliado, tendo por objeto obras complexas - clássicas, entre outras. A leitura exigida depende de uma série de observações formais que impede qualquer investimento pessoal do leitor. O texto é quase sempre um pretexto para a utilização de ferramentas de análise, sendo, portanto, uma rotina sem alma.

Na universidade, o excesso de formalismo gera uma leitura erudita e eficaz, mas desencarnada. Michel Picard (1986, p. 96) e J. M. Delacomptée (2004, p. 48) denunciam a aridez dessa tecnicidade brilhante, dessa "decodificação racionalista" que transforma os estudantes em "primatas eruditos"... "um pouco menos de ciência e um pouco mais de consciência" reclama J. M. Delacomptée. Em seu ensaio O demônio da teoria, Antoine Compagnon (1998, p. 164) constata igualmente que na leitura escolar e universitária o leitor encontra-se "fora de jogo".

Estabelecida a responsabilidade da leitura escolar (que se quer, ao mesmo tempo, erudita, objetiva e neutra), devemos, então, transformar a relação com o texto, reintroduzindo a subjetividade na leitura, humanizando-a, retomando-lhe o sentido.

A observação dos grandes leitores - escritores, críticos literários, filósofos - mostra que eles não renunciam a si mesmos quando leem e é seu investimento subjetivo que garante o valor dessa leitura (Proust, Gide, Manguel, Dumayet, Serres, Tremblay, etc). Isso nos convida a receber, na sala de aula, as "experiências de leitura" e, na pesquisa, a observar leituras liberadas de protocolos e normas escolares.

Na obra citada, Compagnon descreve com lucidez e finura a complexidade da leitura, lugar de tensões diversas entre o texto e o leitor:

a experiência de leitura, como toda experiência humana é sempre uma experiência dúbia, ambígua, estilhaçada: entre compreender e amar, entre a filologia e a alegoria, entre a liberdade e a restrição, entre a atenção ao outro e a preocupação consigo mesmo. (COMPAGNON, 1988, p. 194)

Constatando a irredutível singularidade das leituras efetuadas por leitores empíricos, ele declara que uma teorização do leitor real é impossível.

Entretanto, se o reconhecimento do sujeito leitor não conduz a uma teorização, ele pode levar, ao menos, a importantes avanços teóricos em relação aos leitores reais. A reflexão epistemológica se exerce em várias áreas - literatura, leitura, escrita - sob os olhares cruzados de pesquisadores advindos de diversos campos das ciências humanas - letras, psicanálise, sociologia, antropologia cultura. O início do século XXI foi, de fato, marcado por importantes mutações epistemológicas, algumas dessas já anunciadas no século anterior por uma profusão de pesquisas sobre leitores empíricos e por uma grande criatividade conceitual. 
Antes de apresentar essas mutações, é preciso dizer que a clareza da apresentação não deve nos iludir sobre a realidade. A constatação de uma mudança de paradigma não implica no desaparecimento da teoria anterior. Uma teoria não é imediatamente substituída por outra. Frequentemente, elas coexistem por um longo tempo antes que uma domine a outra. Os fatores de resistência são diversos e de origem variada - ideológica, ética, etc. A reviravolta pode ser efetiva em um dado espaço e sua difusão é, em geral, relativamente restrita ou lenta. E ela não é irreversível. Além disso, essas mutações impactam diferentes níveis: algumas afetam o aparato teórico com o qual pensamos a leitura literária, outras apresentam aspectos singulares que podem ser compreendidos como efeitos das primeiras.

\section{I . Mutações epistemológicas}

\section{A literatura como ato de comunicação: a importância da recepção}

A primeira dessas mutações é ainda frágil e diz respeito à concepção de literatura até então essencialmente definida por sua autorreferencialidade. De fato, a concepção de literatura como um conjunto autônomo de textos com finalidade estética prevaleceu por um longo tempo (e ainda prevalece) tanto no sistema escolar como na universidade. Nessa concepção, a leitura literária relativamente erudita se apoia nas teorias contemporâneas de texto nas quais a poética ocupa um lugar privilegiado. É apenas na virada dos anos 2000 que se generaliza na França a noção de comunicação literária presente, entretanto, nos programas de segundo grau desde a década anterior e, na crítica universitária, há mais tempo, uma vez que Todorov, já em 1984, em Critique de la critique, defendia com veemência a transitividade da literatura:

\footnotetext{
Há duzentos anos, nos repetem que a literatura é uma linguagem que encontra sua finalidade em si mesma. Já é tempo de revisitarmos as evidências que não deveriam ter sido esquecidas: a literatura relaciona-se com a existência humana, ela é um discurso orientado em direção à verdade e à moral [...] a literatura é um ato de comunicação, o que implica dizer que há uma possibilidade de compreensão devido a valores comuns. (TODOROV, 1984)
}

Na escola, essa mudança maior de perspectiva esteve relacionada à atenção dada às teorias da recepção que destacavam o papel do leitor na atualização do texto. A leitura literária se inscreve, então, numa teoria do texto que postula o leitor implícito ou virtual (ou Modelo) ao qual o leitor real, o aluno, deve esforçar-se para parecer. Ainda assim, apesar desse reconhecimento institucional, a comunicação literária é continuamente negada nas práticas que continuam a destacar quase que exclusivamente a análise formal.

É claro que dizer que a literatura é uma prática artística de comunicação é reconhecer a importância da recepção e isso já é um avanço importante, mas a recepção ainda é pensada de uma maneira abstrata, conceitual, a partir do leitor inscrito no texto, capaz de atualizar todas as suas virtualidades. 
A reflexão sobre o sujeito leitor conduz a uma importante mudança de paradigma. Passamos de uma concepção de leitura literária organizada em torno de um Leitor Modelo a uma concepção de leitura literária mais liberal que se interessa pela reconfiguração do texto pelo leitor real e apresenta modos de realização plurais. Trata-se de uma ruptura epistemológica ainda mais profunda que a precedente, uma vez que ela se dedica, de forma efetiva, a uma mudança de foco, da interpretação do texto à atividade do leitor e à relação desse último com o objeto. Essa mudança apoia-se principalmente nos trabalhos de Pierre Bayard, Bruno Clément, Jean Bellemin-Noël e Gérard Langlade e também nos ensaios sempre "atuais" de Michel de Certeau e Italo Calvino.

A atividade do leitor, a maneira pela qual ele se investe no texto para elaborar o seu "texto do leitor" (noção estabelecida por P. Bayard) reteve, de forma especial, a atenção dos pesquisadores em didática da literatura. O texto reconfigurado pelo leitor assinala ao mesmo tempo a apropriação do primeiro pelo segundo e a criatividade desse último. Ele é resultado, de acordo com J. Bellemin-Noël ${ }^{2}$, de uma relação única e singular entre o texto do autor e a vida do leitor. Ele é produto e marca de uma "experiência de leitura".

A observação (por meio de diários de leitura) dos processos de singularização do texto, as tentativas de descrição da forma (instável, provisória) que o texto toma na consciência de quem o recebe, estão no centro das pesquisas atuais. A teorização de G. Langlade $(2004 ; 2006)$ sobre a atividade ficcionalizante do leitor durante o processo de leitura e o colóquio internacional sobre o "texto do leitor" organizado em Toulouse (2008) produziram alguns progressos em relação ao conhecimento do leitor real.

\section{De uma relação distanciada com o texto a uma distância implicada e flutuante: a identificação reabilitada}

O interesse pelas experiências de leitura nos convida a pensar sobre a experiência primeira de leitura e o movimento de empatia que produz uma compreensão profunda do texto. Na perspectiva didática, isso nos conduz a reconsiderar a leitura literária em relação à leitura cotidiana, a entender essa relação como um continuum e não como uma ruptura, a observar, em situações de leitura diversificadas (interpostas, situadas entre esses dois polos), as formas que essa relação com o texto toma.

Essa mudança de perspectiva que recusa a clivagem entre leitura cotidiana e leitura literária, interessando-se, pelo contrário, pela complexidade fecunda de suas relações acompanha a reabilitação do fenômeno da identificação. Por muito tempo tratada como uma conduta regressiva, a identificação é, hoje em dia, valorizada como uma experimentação complexa do vivido ficcional.

"o que denomino texto é para mim, se quisermos que essa palavra tenha algum interesse, sempre “meu texto": uma versão da obra para meu uso próprio, com vazios em relação àquilo que não me diz respeito e destaques em relação àquilo que me fez sonhar, muitas vezes seguindo uma ordem que tem pouco a ver com a sequência explícita da intriga” (BELLEMIN-NOËL, 2001, p. 199). 
A identificação aparece ainda como a condição para o reencontro com a alteridade. Essa experiência é a de um sujeito ativo, como nos mostra H. R. Jauss em seu Petite apologie de l'expérience esthétique (1975) e V. Jouve em seu l'Effet personnage (1992); trata-se de uma experiência intensa cuja abordagem fenomenológica ilumina o fato de que ela não depende apenas dos afetos, mas engaja todo o ser do leitor: seu psiquismo, seu corpo, seu intelecto. Trata-se, então, de uma identificação ativa no cerne mesmo da leitura, uma identificação que não se limita ao gesto de adesão, podendo tomar a forma de uma reação polêmica feita também de recusa.

No fim das contas, o que está em jogo na identificação, de forma mais ou menos inconscientemente, é a própria identidade do sujeito. A leitura é sempre uma afirmação de si diante do texto e cada leitura conduz a uma recomposição das representações e do repertório de valores do leitor. Por meio da identificação, o sujeito descobre a alteridade que está nele mesmo. Como escreve B. Clément: "para aquilo que pode haver em mim de outro quem melhor que o Outro para manifestar?” (CLÉMENT, 1999, p. 16).

Esse mesmo movimento crítico pede uma revisão do valor atribuído à noção de distanciamento, excessivamente ligada ao estudo formal e ao julgamento estético. A distância existe em toda interpretação, sustentando o julgamento ético ou ideológico sobre o universo representado. Trata-se da distância intelectual ligada à leitura como forma de conhecimento e busca de sentido, uma distância necessária e que se encontra tensionada com a noção de identificação.

De fato, a relação com o texto não se deixa apreender pelas dicotomias de distância/ proximidade ou empatia/distanciamento que designam posturas excludentes. A realidade é mais complexa: durante uma mesma leitura, o investimento psicoafetivo pode ser alternado ou combinar-se com o distanciamento crítico num trançado singular. A relação com o texto (que é também um jogo de forças - dominação/submissão) é flutuante, descontínua, colocando em cena facetas diversas da identidade do leitor. O colóquio de Rennes sublinhou inúmeras vezes a existência e pertinência dessas camadas identitárias.

\section{Da interpretação hermenêutica à atividade interpretativa guuiada pelos movimentos da subjetividade}

Na escola, como na universidade, por muito tempo, distinguimos e hierarquizamos as duas operações mentais da compreensão e da interpretação. Elas corresponderiam a dois níveis de leitura, sendo que compreensão literal seria anterior a qualquer interpretação. Essa escolha teórica levou a um modelo de leitura escolar em dois tempos, organizando-a linearmente numa lógica que levaria do simples ao complexo. Se a compreensão precisa apenas do texto, a interpretação erudita supõe o aporte iluminado das ciências humanas na produção de significados mais ricos.

Ora, as pesquisas contemporâneas em teoria literária e em didática (P. Ricoeur; C. Tauveron) contestam essa hierarquia e mostram que durante o processo de elaboração do sentido, compreensão e interpretação se alternam e que a interpretação ocorre em geral em primeiro lugar, servindo de guia à compreensão.

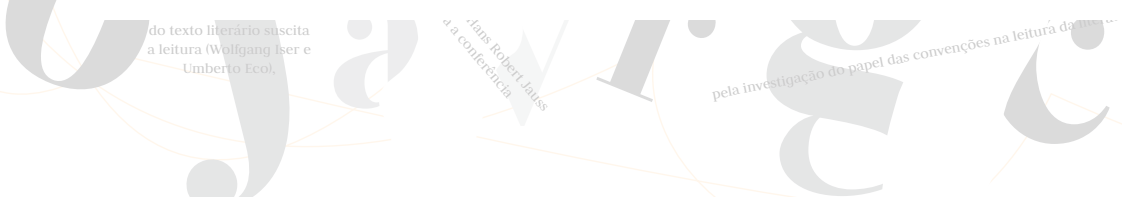


De fato, os caminhos que conduzem à significação são diversos e confusos (complexos): os movimentos da subjetividade durante a atividade leitora reforçam a concepção não linearizada do processo de compreensão/interpretação.

Mas, nas experiências de leitura, a subjetividade intervém ainda de outra maneira: frequentemente o leitor se apropria do texto, utilizando-o e interpretando-o ao mesmo tempo. Em sua obra Seis passeios no bosque da ficção, U. Eco distingue essas duas operações e descarta a "utilização" por ser uma atividade mais pessoal. Mas, no dia a dia, na realidade das leituras, principalmente a dos alunos, essas duas operações são raramente separadas. Além disso, se nos referirmos ao Diário de um leitor, de A. Manguel (2004), perceberemos que esse grande leitor utiliza as obras que leu: elas as desvia, conforme seu humor, para um uso pessoal. Seu diário ilumina um aspecto essencial da atividade leitora que podemos definir como a atividade de reliance (E. Morin): ela desnuda o jogo de associações e reminiscências estimulado pela leitura. Destaca-se assim a ideia de que toda a leitura é associativa, que o pensamento está sempre em movimento, que há um ir e vir caótico (e acidentado!), indisciplinado entre o mundo do texto e o mundo do leitor.

\section{Da cultura literária à biblioteca interior}

Ainda mais aberta e mais próxima da realidade, a cultura literária que se deseja encorajar é esse espaço simbólico composto ao mesmo tempo de referências pessoais e de referências comuns reconfiguradas pela subjetividade do leitor. Mais liberal e mais empírica, essa concepção de cultura literária não pode ser avaliada por meio de referências legítimas e quantificáveis; ela releva um olhar menos exterior, estando assentada em três noções teorizadas recentemente: o texto do leitor ${ }^{3}$, a interleitura e a biblioteca interior.

Sobre a noção de "texto do leitor", como vimos, cada texto lido é reconfigurado pelo leitor. "Como cada leitor constitui sua própria rede de indícios, não é o mesmo texto que é lido”, escreve Pierre Bayard (1998, p. 90), de tal forma que é ilusório acreditar que referências comuns construam uma cultura idêntica.

Já a “interleitura”, noção criada por Jean Bellemin-Noël, designa a rede de relações que um leitor estabelece entre textos "mesmo se o texto em questão não fornece explicita e textualmente as indicações que permitem a construção dessa rede” (BELLEMIN-NOËL, 2001, p. 12). Para o leitor, o texto adquire uma significação mais complexa, amplificada ou nuançada pelos ecos dos textos lidos anteriormente. Além disso, e de forma mais imediata, o texto é lido em relação a outros objetos culturais e à experiência vivida - presente ou passada - do leitor'. A leitura interpela ou se conforma à experiência de mundo do leitor.

Enfim, a noção de biblioteca interior é definida por P. Bayard como:

o conjunto de livros [...] a partir dos quais qualquer personalidade se constrói, organizando sua relação com os textos e com os outros. Uma biblioteca na qual figuram

Ver os anais do colóquio organizado em Toulouse em 2008 baseado na noção proposta por P. Bayard: C. Mazauric, M.-J. Fourtanier, G. Langlade (org.), Le Texte du lecteur (volume 1) et Le Texte du lecteur en formation (volume 2), Peter Lang, 2011.

Fenômeno discutido por R. Ingarden em L'CEuvre d’art littéraire (1983). 
certos títulos específicos, mas que é principalmente constituída de fragmentos de livros esquecidos e de livros imaginários por meio dos quais apreendemos o mundo [...] Não nos contentamos de abrigar essas bibliotecas, nós somos também a totalidade desses livros acumulados que nos produziram também. (BAYARD, 2007, p. 74)

Essa é a versão interiorizada da cultura literária, um conjunto limitado e móvel de dados concretos e imaginários, marcados pela singularidade do sujeito e dando-lhe forma, ao mesmo tempo. Se, de fato, durante a leitura, o leitor altera o texto para fazer o "seu texto" , cada leitura reconfigura essa identidade do leitor. A obra de Brigitte Louichon, La Littérature après coup (2009), testemunha essa contínua construção identitária.

Assim concebida, a cultura literária é evidenciada pelas associações livres, pelas relações, pelos ecos mais ou menos longínquos que o leitor estabelece entre suas leituras e o mundo (o que transparece na escrita livre dos diários de leitura).

\section{Consequências para o ensino da literatura}

Essa reflexão teórica nos convida a repensar o ensino da literatura de forma a melhor conjugar o procedimento crítico e a abordagem subjetiva dos textos. Isso pode ser traduzido nas três seguintes prioridades:

1. Preferir, em sala, uma abordagem menos formal, mais sensível. No sistema escolar francês, essa é uma das funções dadas à "leitura cursiva", leitura prescrita pelo professor e efetuada no espaço privado de modo que o leitor possa ser envolvido pelo imaginário do texto, sonhar e colher no texto aquilo que lhe convém. Mas essa abordagem sensível também deveria ter igualmente lugar no ensino básico de modo a dar sentido à atividade da leitura literária. Ela diz respeito, então, também à leitura analítica realizada em aula. Ora, como sabemos por nossa experiência, a leitura literária em sala é um lugar de aprendizagens múltiplas e “o gesto de ler desaparece sob o ato de aprendizado" (BARTHES, 1984, p. 40-41).

Essa tensão entre a transmissão de saberes e leitura propriamente dita faz parte da leitura escolar que tende a assimilar estudo e leitura. E ela é mais acentuada quando o ensino da literatura depende de trechos curtos e até curtíssimos, como é o caso do ensino de FLS e FLE ${ }^{6}$. É preciso criar, então, qualquer que seja a heterogeneidade cultural, social e cognitiva dos alunos, uma relação feliz entre leitura e literatura. Experiências realizadas em “zonas sensíveis” mostram que isso é possível. Filmes ${ }^{7}$ realizados recentemente mostram como alunos de classes multiculturais, engajados em um projeto, apaixonam-se pelos grandes clássicos estudados em sala e como essas leituras os transformam.

Eco de Jean Bellemin-Noël. Ver nota 2.

${ }^{6}$ Français Langue Seconde (FLS) [Francês Segunda Língua] e Français Langue Etrangère (FLE) [Francês Língua Estrangeira].

${ }^{7}$ L'Esquive, de Abdellatif Kechiche (2002), apresenta estudantes de um subúrbio parisiense envolvidos no ensaio da peça Les jeux de l'amour et du hasard de Marivaux; Nous Princesse de Clèves, de Régis Sauder (2011), mostra como os alunos de uma classe multicultural em um colégio em Marselha se apropriam, junto com seus pais, do romance de Madame de La Fayette, praticando sem saber a leitura atualizadora preconizada Yves Citton (2007). 
De forma concreta, isso significa que é preciso dar espaço em sala aos textos dos leitores. Isso não significa que precisamos encorajar todas as derivas ou delírios ou toda forma de solipsismo e nem renunciar ao rigor e ao conhecimento. Trata-se de suscitar e acolher elaborações semânticas diferentes e aceitar a ideia do mal-entendido como um elemento constitutivo de qualquer procedimento interpretativo. No ensino médio e também na universidade, trata-se de instituir a subjetividade, de encorajar o leitor a ir mais a fundo em si mesmo de modo a descobrir seu próprio pensamento; na aventura interpretativa, é preciso ter a coragem de se aventurar não apenas no desconhecido do texto, mas no desconhecido que está em nós mesmos. Para o leitor, o texto é uma oportunidade de conhecer, de ler a si mesmo.

2. Privilegiar a leitura em ato ao invés do resultado da leitura. É a atenção dada ao processo, pelo professor e pelos alunos, que faz a formação do leitor. A prática dos diários de leitura é uma forma privilegiada de explorar o processo de leitura, observar como se dá a lógica associativa (intertextualidade e interleitura), como se elabora, por afirmação de si ou por questionamentos, a construção identitária. Esses escritos, nos quais se pode observar a complexidade irredutível da relação com o texto na leitura, são também um objeto privilegiado para os pesquisadores: atualmente $^{8}$, na França, muitos colóquios e jornadas de estudos estão sendo a ele dedicados. A leitura em ato também pode ser percebida a partir das trocas em classe. É possível suscitar nos alunos certos procedimentos metacognitivos que os conscientizem de seus caminhos interpretativos. Isso é particularmente importante no caso de erros de leitura, quando é necessário refazer os movimentos do pensamento e compreender de onde vem a interpretação errada.

3. Enfim, em relação à questão da norma e do estatuto das leituras singulares em classe, me parece que seria dar concretude à legitimidade teórica do conflito de interpretações, trabalhar com as leituras contraditórias, preferir a noção de espaço intersubjetivo ao conceito de arquileitor (que é, com efeito, a representação de um leitor omnisciente). A busca de uma compreensão mútua mais aberta e menos consensual destaca uma formação intelectual na qual a recusa das certezas e a manutenção da polissemia (de uma polissemia aceitável) são valores a serem buscados.

\section{A formação dos professores, lugar de reflexão, de experimentação e de pesquisa}

As mudanças profundas implicadas nas importantes transformações epistemológicas descritas no início deste artigo correm o risco de transformarem-se em letra morta na ausência da difusão dos avanços da pesquisa. Sem esperar pela institucionalização desse conhecimento, isto é, seu reconhecimento oficial atestado por sua presença nos textos que regulam a política educativa de um país, é possível dar início a sua execução e enriquecer a reflexão corrente.

A formação dos professores é frequentemente apresentada como a interface entre a pesquisa e a classe. Os professores iniciantes experimentam em suas classes os novos

Jornada de Estudos (23 de maio) em Gennevilliers; Colóquio de Grenoble (6 e 7 de julho de 2012). 
saberes provenientes da pesquisa podendo também, de certa maneira, enriquecê-la. Parece-me importante, como já havia afirmado ano passado em Rabat, no $12^{\circ}$ Encontro de Pesquisadores em Didática da Literatura, integrar a pesquisa ao ato didático. É sem dúvida o melhor meio de lutar contra o dogmatismo e o aplicacionismo que reificam as práticas, privando-as de sentido.

1. Formar-se como leitor: uma das prioridades dessa formação é formar leitores. É preciso que os professores em formação adquiram para si e para os alunos uma cultura literária, refletindo sobre suas experiências de leitura e construindo sua identidade de leitor ${ }^{9}$. Essa necessidade é ainda mais premente no caso dos professores dos primeiros ciclos do ensino fundamental que não são especialistas e descobrem, às vezes, e até frequentemente, a literatura antes de começarem a ensinar (em particular a literatura infanto-juvenil que é um campo novo, em pleno desenvolvimento). Os questionamentos que podem ter sobre sua própria relação com a literatura, sobre sua própria prática de leitura literária de certo modo prefigura a reflexão a ser feita em relação às experiências de leitura de seus alunos. Essa refletividade que produz conhecimento metalexical é parte integrante tanto de sua cultura literária quanto de sua cultura profissional.

2. Escutar os leitores reais em suas comunidades interpretativas: entre os gestos profissionais que os professores em formação devem aprender - estimular a atividade dos alunos, gerenciar o tempo de fala de cada um, ficar em segundo plano no momento oportuno, etc. - há um que condiciona a implicação dos alunos: é a escuta (escuta pelo professor, escuta mútua entre os alunos). A relação com a literatura que se instaura pela leitura em sala depende muito das relações que se estabelecem na "comunidade interpretativa". É importante que os textos dos leitores, em suas singularidades, sejam legitimamente admitidos em classe e possam ser submetidos à reflexão coletiva. Isso supõe o estabelecimento de um clima de confiança de modo que a distância em relação àquilo que o texto postula ou implica ou simplesmente em relação a uma significação mais consensual derivada da intersubjetividade não seja estigmatizada. As interpretações divergentes, as leituras que não correspondem à "cooperação interpretativa" esperada - aquelas que rompem o equilíbrio harmonioso entre os "direitos do texto" e os "direitos do leitor" - são interessantes na medida em que refratam a imagem dos leitores reais, nos informando sobre os obstáculos encontrados. Querendo ou não, o professor em formação é confrontado com autênticos problemas de pesquisa.

3. Contribuir com a pesquisa em andamento sobre atitudes e emoções: observamos que hoje em dia é menos a análise do texto (ou da obra) em si, o resultado da leitura, que interessa os pesquisadores e mais a relação que se tece entre o leitor e o texto, o processo de leitura em si.

É verdade que há competências incontornáveis a serem desenvolvidas por todo e qualquer leitor, como a atenção ao texto - à superfície do texto, à sua matéria e ao texto em sua globalidade - ou como a capacidade de selecionar indícios textuais para justificar

A prática dos autorretratos ou de autobiografias de leitores permite construir uma imagem de si próprios, provisória, frágil, parcial, funcionando, principalmente, como espaço de questionamento. 
uma interpretação. Há outras mais sutis ainda, que são fruto da experiência, como admitir que possam existir zonas de sombras e de incertezas no texto (isso acontece muito na literatura contemporânea) ou que uma interpretação não esgota o texto (ela não pode ser exaustiva). Mas, para que o encontro com a obra possa tornar-se um evento para o leitor, para que ele aceite confrontar-se com a alteridade, certas condições (ou competências ou atitudes) são necessárias. Um determinado número de pesquisadores (tais como Chabanne, 2009) tem precisamente explorado esse campo de atitudes que condiciona a recepção estética, tanto na esfera afetiva como cognitiva. Essas atitudes podem ser ensinadas e cultivadas. É o caso da disponibilidade necessária ao encontro com uma obra: lendo, o sujeito expõe-se, renuncia a suas preocupações, abre-se ao universo textual, a sua axiologia, a seus valores e aceita transformar-se. É o que vemos no desejo de literatura, como mostra Carol Battistini em sua tese dedicada à iniciação literária de crianças no ensino fundamental. Isso também é verdade para o julgamento de gosto cuja relatividade histórica, social, cultural e, em uma palavra, contextual não ignoramos hoje.

Enfim, as pesquisas recentes sobre o "texto do leitor", sobre aquilo que constitui sua textura - fragmentos verbais, imagens mentais - tem se concentrado em abordagens fenomenológicas de modo a observar os efeitos do texto sobre o eu leitor. Primeiramente nas salas do ensino médio, mas também na universidade, foram inventados dispositivos para captar a "escuta flutuante" dos alunos, para ensiná-los a identificar as sensações e as emoções que os atravessam ou que abrigam durante a leitura. O fluxo de imagens mentais surgidas durante a leitura deu igualmente lugar a análises que destacam a singularidade irredutível da leitura. De fato, com a postura da escuta flutuante e da disponibilidade para si e para o texto, trata-se de ampliar a receptividade dos leitores, de incitá-los a estarem atentos a seus corpos para que possam sentir, de maneira mais intensa, os efeitos da obra em si, aprendendo a "ler com o corpo"10, a descobrir, identificar e nomear as sensações e emoções experimentadas durante a leitura; de fato, é importante captá-las, colocá-las em palavras para que não desapareçam. Só assim elas podem tornar-se o terreno da experiência estética.

A reflexão atual sobre o papel fundamental das emoções na recepção das obras literárias não é propriamente uma novidade... Já no começo do século XX, Kafka destacava a importância da recepção emotiva com a imagem do "machado que rompe o mar gelado em nós”"I mas, por anos, as práticas da leitura escolar esqueceram-se dessas evidências.

É tempo então de recolocar o sujeito leitor no centro da leitura, de lembrar que cognição e emoção têm relações fecundas. Para os professores, trata-se de encorajar os alunos a experimentar uma leitura sensível, sensual, na qual eles consigam engajar todo o seu ser. Como escreveu J. Leenhardt : "Na atividade leitora concreta, o trabalho imaginário ultrapassa constantemente os limites determinados pelas modalidades do funcionamento da inteligência humana. Se ele as ultrapassa, é porque a leitura, como

10 A expressão não é nova. Em 1989, em Lire le temps, M. Picard escreveu : « O verdadeiro leitor tem um corpo, ele lê com ele ». Ver em MAZAURIC, C.; FOURTANIER, M.J.; e LANGLADE, G. (2011, p. 144-147) o protocolo imaginado por Nathalie Brillant-Rannou para auxiliar os alunos a exprimir sua recepção após a leitura de poemas.

II Carta a Oscar Pollack, de janeiro de 1904.

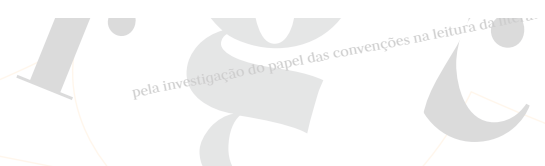


atividade especificamente humana, coloca em jogo a totalidade de nossas aptidões. Podemos, consequentemente, dizer que é o corpo humano em sua totalidade que sedia o processo de leitura" (LEENHARDT, 1987, p. 310).

\section{Referências Bibliográficas}

BARTHES, R. “Sur la lecture”. In: Le Bruissement de la langue. Paris: Seuil, 1984. BAUDELOT, C.; CARTIER, M.; DETREZ, C. Et pourtant ils lisent. Paris: Seuil, 1999. BAYARD, P. Comment parler des livres qu'on n’a pas lus. Paris:Minuit, 2007. BELLEMIN-NOËL, J. Plaisirs de vampire. Paris: PUF, 2001.

CALVINO, I. Pourquoi lire les classiques? Paris: Points, 1991/1996.

CHABANNE, J. C. "Enseigner des attitudes ? Une notion omniprésente mais problématique pour la littérature et les disciplines culturelles et artistiques". In: DUBOIS-MARCOIN, D. (org.), Français/littérature, socle commun: quelle culture pour les élèves, quelle professionnalité pour les enseignants? Lyon: INRP, 2009, p. 49-70.

CLÉMENT, B. Le Lecteur et son modèle. Paris: PUF, 1999.

COMPAGNON, A. Le Démon de la théorie. Paris: Seuil, 1998.

DELACOMPTÉE, J. M. «Un peu moins de science, un peu plus de conscience». Le Français aujourd'hui, n¹45, Le littéraire et le social, 2004.

ECO, U. Lector in fabula. Paris: Grasset,1985.

. Les Limites de l'interprétation.Paris: Grasset, 1992.

Six promenades dans les bois du roman et d'ailleurs. Paris: Grasset- Fasquelle, 1996.

FISH, S. (1980). Quand lire c'est faire. L'autorité des communautés interprétatives. Paris: Les Prairies ordinaires, 2007

INGARDEN, R. L'EEuvre d'art littéraire. Lausanne: L'âge d'homme, 1983.

GENETTE, G. L'CEuvre de l'art, la relation esthétique. Paris: Seuil, 1997.

ISER, W. L'Acte de lecture: Théorie de l'effet esthétique. Bruxelles: Mardaga, 1985.

JAUSS, H.R. Pour une esthétique de la réception. Paris : Gallimard, 1978.

JOUVE, V. (1992) : L'Effet-personnage dans le roman. Paris: PUF, 1992.

"La lecture comme retour sur soi. De l'intérêt pédagogique des lectures subjectives”. In : ROUXEL, A.; LANGLADE, G. Le sujet lecteur. Lecture subjective et enseignement de la littérature, PUR, 2004.

LANGLADE, G. Lactivité fictionnalisante du lecteur. In: BRAUD, M.; LAVILLE, B.; LOUICHON, B. (org). Les Enseignements de la fiction. Bordeaux: Modernités n 23, PUB, 2006.

"Le sujet lecteur auteur de la singularité de l'œuvre". In: ROUXEL, A.; LANGLADE, G. Le Sujet lecteur. Lecture subjective et enseignement de la littérature. PUR, 2004.

LANGLADE, G. \& ROUXEL, A. Des références critiques pour quoi faire?. Le Français Aujourd'hui 160. La critique pour quoi faire? 2008, p. 53-59.

LEENHARDT, J. Les instances de la compétence dans l'activité lectrice. In : PICARD, M. (ed.) La Lecture littéraire. Paris: Clancier-Guénaud, 1987.

LOUICHON, B. La Littérature après coup. Rennes: PUR, 2009.

MANGUEL, A. Journal d'un lecteur. Arles: Actes Sud, 2004. 
MAZAURIC, C.; FOURTANIER, M. J.; LANGLADE G. (org.). Le Texte du lecteur. Berne: Peter Lang, 2011a.

. Le Texte du lecteur en formation. Berne: Peter Lang, 2011b.

PETIT, M. Éloge de la lecture. Paris: Belin, 2002.

. L’Art de lire ou comment résister à l'adversité. Paris: Belin, 2008.

PICARD, M. La Lecture comme jeu. Paris: Minuit, 1986.

RICOEUR, P. Temps et récit en débat. Paris: Le cerf, 1990.

ROUXEL, A.; LANGLADE, G. (org.) Le Sujet lecteur. Lecture subjective et enseignement de la littérature. Paris: PUR, 2004.

ROUXEL, A. Enseigner la lecture littéraire. Paris: PUR, 1996.

TODOROV, T. Critique de la critique. Paris: Seuil, 1984.

La Littérature en péril. Paris: Flammarion, 2007.

ArTigo ReCEBIDO EV: 01 jul. 2012

ARTigo ACEITO EV: 20 jul. 2012

ReFERÊNCIA ELETRÔNICA: ROUXEL, Annie. Mutações epistemológicas e o ensino da literatura: o advento do sujeito leitor. Tradução de Samira Murad. Revista Criação \& Crítica, n. 9, p. 13-24, nov. 2012. Disponível em: <http://www.revistas.usp.br/criacaoecritica>. Acesso em dd mmm aaaa. 